BIOKEMISTRI 19(1):17-21 (June 2007)

This article is downloadable online in PDF

format at http://www.bioline.org.br/bk

Printed in Nigeria
An international journal published by the

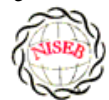

OVigerian Bociety for Ëxperimental ß̊iology

\title{
Hepatoprotective effects of Garcinia kola seed against hepatotoxicity induced by carbon tetrachloride in rats
}

\author{
Mathew O. WEGWU ${ }^{1}$ and Blessing C. DIDIA ${ }^{2}$ \\ ${ }^{1}$ Toxicological Unit of Biochemistry Department, University of Port Harcourt, P.M.B. 5323, \\ Port Harcourt, Nigeria \\ ${ }^{2}$ Department of Anatomy, University of Port Harcourt, P.M.B. 5323, Port Harcourt, Nigeria
}

Received 9 February 2006

MS/No BKM/2006/003, (C) 2007 Nigerian Society for Experimental Biology. All rights reserved.

\begin{abstract}
The protective effects of Garcinia kola against a dose of Carbon-Tetrachloride $\left(\mathrm{CC}_{4}\right)$ induced liver damage in experimental rats were investigated. The $\mathrm{CCl}_{4}$ induction (administered intraperitoneally, $0.5 \mathrm{~m} 1 / \mathrm{kg}$ body weight in olive oil $-0.5 \mathrm{ml} / \mathrm{kg}$ body weight) led to significant increases in the levels of serum aspartate and alanine amino transferases, alkaline phosphatase and lipid peroxides in $\mathrm{CC}_{1}$ intoxicated rats. Pretreatment with varied concentrations of Garcinia kola diets (1\%,5\% and 10\%) and vitamin E (9\%,) for 21 days prior to $\mathrm{CCl}_{4}$ administration resulted in significant decreases in Liver marker enzymes and lipid peroxides. These findings suggest that Garcinia kola seed may be acting as a natural antioxidant that prevents hepatic oxidative stress induced by $\mathrm{CCl}_{4}$
\end{abstract}

Keywords: Hepatoprotective; Garcinia kola; Liver marker enzymes; Lipid peroxides

E-mail: wevic2000@yahoo.com Tel: +2348068698933 


\section{INTRODUCTION}

The demand for therapeutic drugs from natural products is on the increase in recent times. This is traceable to the realization that plant products contain active constituents that are capable of curing majority of man's diseases. Indeed, drugs of natural origin are the only widely used hepatoprotectives ${ }^{1}$.

Garcinia kola belongs to the Family Clusiaceae guttiferae and contains a complex mixture of biflavonoids, prenylated benzophenones and xanthones $^{2}$. The plant has shown antiinflammatory, antimicrobial, pharmacological and antiviral properties. It has been confirmed that seeds of Garcinia kola contain energyyielding nutrients (proteins, lipids, carbohydrates) and minute quantities of Kolaviron (consisting of biflavonoids GB-1, GB-2 and Kolaflavone) $)^{3}$. The seeds of Garcinia kola have been employed in many herbal preparations in Nigeria for the treatment of ailments ranging from laryngitis, bronchitis to liver disorders ${ }^{4}$.

Trichloromethyl radicals are generated from $\mathrm{CCl}_{4}$, in vivo, which stimulate a sequence of biochemical reactions that lead to the initiation of lipid membrane peroxidation ${ }^{5}$. The ethanol inducible isoform of the $\mathrm{P}_{450}$ cytochrome is believed to play an active role in this process. Indeed, the process of $\mathrm{CC}_{4}$ induction of lipid peroxidation provides useful information that could be explored in examining antioxidant properties of natural products. The aim of this study was to assess the ability of Garcinia kola seeds to exhibit antioxidant actions against $\mathrm{CCl}_{4}$ - induced liver damage in rats.

\section{MATERIALS AND METHODS}

The seeds of Garcinia kola (purchased from Choba market in Rivers State, Nigeria) were peeled, sliced and dried in the air for 5 days. The dried, sliced feeds were ground into flour with an electric blender (Model MX $795 \mathrm{~N}-\mathrm{National})^{6}$. Male albino rats of the Wistar strain (140g-160g) were obtained from the University of Port Harcourt animal house. They were housed in Griffin and George modular cage system and left to acclimatize to laboratory conditions for 7 days prior to commencement of work. The animals were fed with a commercial pelleted diet (purchased from Top Feeds, Nigeria Ltd. Port Harcourt, Nigeria) and water ad libitum.

\section{Experimental procedure}

The rats were divided into six groups with each group comprising five animals. Rats in groups 1 and 2 received the pelleted diet and water, while those in groups 3, 4 and 5 were fed with diet formulated with the flour of Garcinia kola and rat pellets as follows: group 3-1\% flour of G. cola; group 4-5\% flour of G. cola; group 5-10\% flour of G. cola

Also, animals in group 6 received diet compounded with vitamin $\mathrm{E}$ and rat pellets $(9 \%$ vitamin E). All the rats in the various groups received their respective diets and water ad libitum for 21 days. On the $22^{\text {nd }}$ day of the experiment, $\mathrm{CCl}_{4}(0.5 \mathrm{ml} / \mathrm{kg}$ body weight in 0.5 olive oil) was administered intraperiteneally to rats in groups 2, 3, 4, 5 and 6. The animals were allowed to fast for 24 hours after which they were anaesthetized in a chloroform saturated chamber ${ }^{7}$. Blood samples were obtained by cardiac puncture from each rat by means of a $5 \mathrm{ml}$ hypodermic syringe and needle. The blood samples were introduced into clean, dry bottles without anticoagulants for serum separation. The bottles and its contents were centrifuged at $5000 \mathrm{~g}$ for 10 minutes (model: MSE - Minor 35 centrifuge). Serum was collected into a clean, dry sample container. The serum levels of L-aspartate aminotransferase (AST), L-alanine transferase (ALT) and alkaline phosphatase (ALP) were measured spectrophotometrically as described by Verly ${ }^{8}$. The liver was excised, washed in ice-cold saline, and homogenized at $0.1 \mathrm{M}$ Tris-HC1 buffer $\left(\mathrm{pH} \quad 7.4 ; 4^{0} \mathrm{C}\right)$ in a homogenizer at $600 \mathrm{rpm}$ for 4 minutes using mortar and pestle ${ }^{9}$. The liver homogenate was employed in assaying the activities of the lipid peroxides as described by Hunter et. $a l{ }^{10}$ and modified by Gutteridge and Wilkins ${ }^{11}$. The mean values of the various groups were compared using analysis of variance (ANOVA) and the level of significance was set at $\mathrm{p} \leq 0.05$. 


\section{RESULTS}

The effects of pretreatment with seeds of Garcinia kola and vitamin E, 21 days prior to
$\mathrm{CC}_{4}$ administration on liver enzymes and lipid peroxides in rats is shown in figures 1 and 2 .

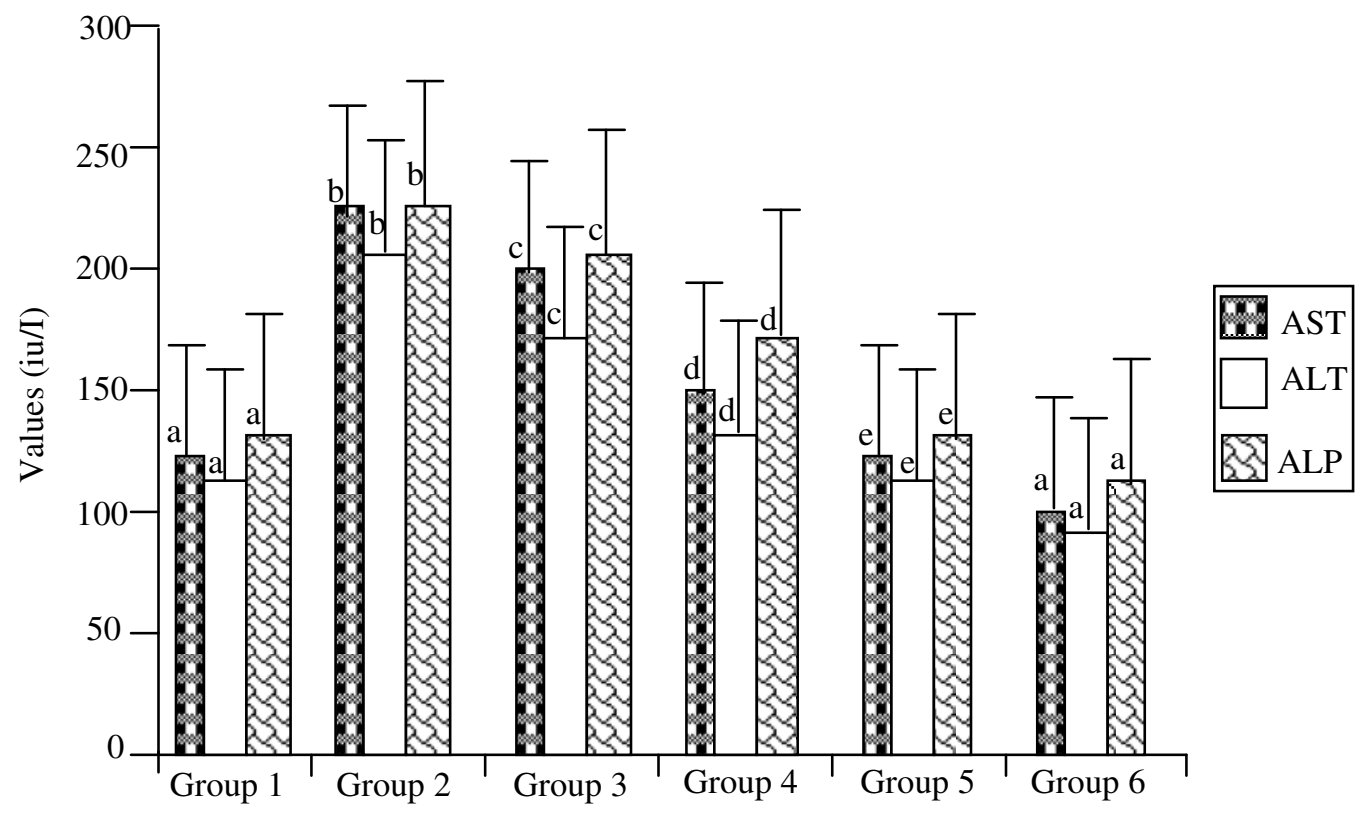

Fig. 1: Effects of varied levels of Garcinia kola and Vitamin E on liver enzymes of rats administered $\mathrm{CCl}_{4}$ (mean $\pm \mathrm{STD} ; \mathrm{n}=5$ in each group). *Values of enzymes with different letters $(\mathrm{a}, \mathrm{b}, \mathrm{c}, \mathrm{d}, \mathrm{e})$ in the respective groups are significantly different at $P \leq 0.05$

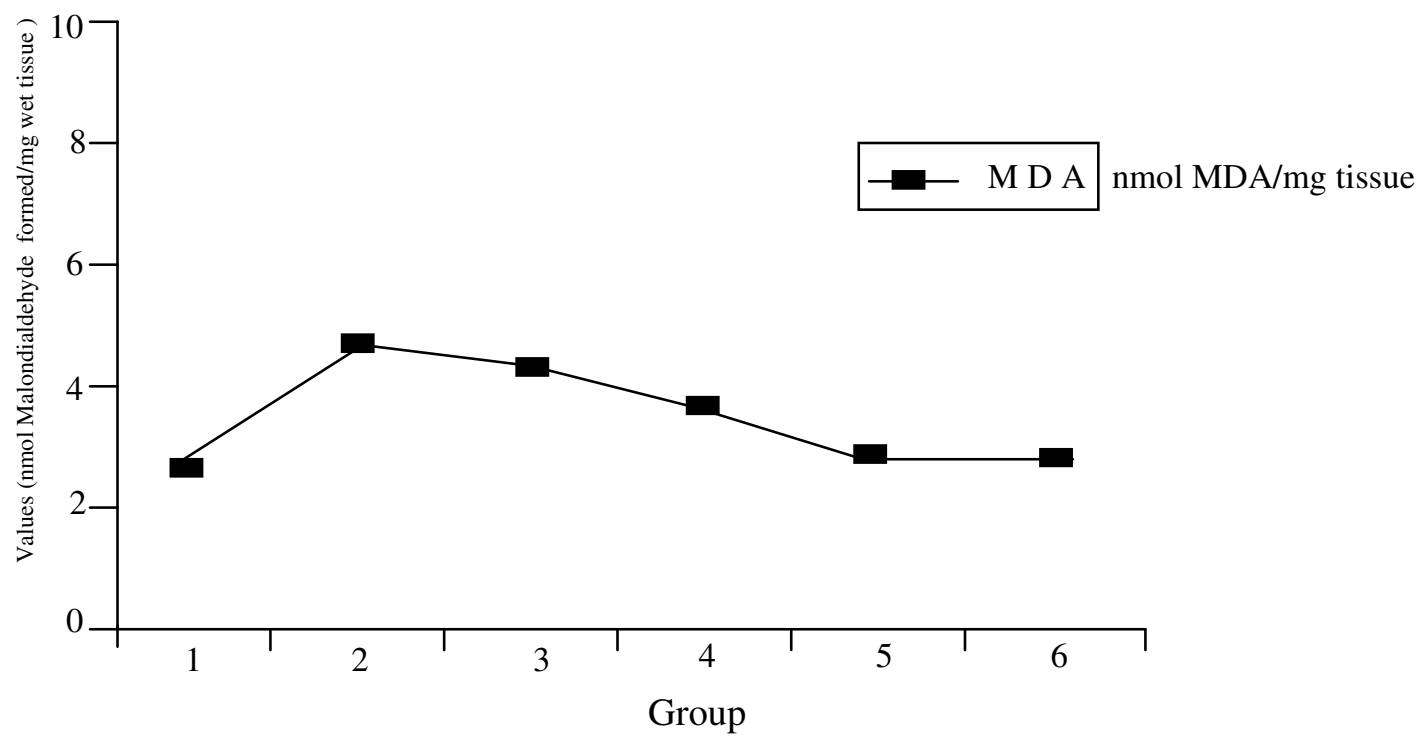

Fig. 2: Activities of lipid peroxides in rats pretreated with Garcinia kola seed and Vitamin E prior to $\mathrm{CCl}_{4}$ administration. 
Group 2 rats that received a single dose of $\mathrm{CCl}_{4}$ showed marked elevation in the levels of liver enzymes when compared with those of the group 1 (control) rats. The pretreated groups 3, 4, 5 and 6 rats showed remarkable decline in the levels of AST, ALT and ALP when compared with group 2 rats that received $\mathrm{CCl}_{4}$ alone.

In the liver tissue, increased levels of lipid peroxides were recorded in the group 2 rats (figure 2). The activities of the peroxides decreased with increase in the amount of the seeds of Garcinia kola in the feed formula. This is evidenced in the values obtained in rats in groups 3, 4, and 5. Similarly, rats in group 6 recorded malondialdehyde values close to those of group 5 and 1 (control) rats.

\section{DISCUSSION}

As elicited by the elevation in the levels of liver marker enzymes (AST, ALT, ALP), $\mathrm{CCl}_{4}$ administration resulted in a significant hepatic damage. Obviously, the elevated levels of these biochemical parameters are a direct reflection of alterations in the hepatic structural integrity. The results of the enzymes obtained in this study corroborates those of Obi, et. $a l^{7}$ and Reinke, et. $a l^{5}$ who reported elevated levels in the serum content of hepatic enzymes in rats administered with $\mathrm{CCl}_{4}$. In particular, the elevation of ALT is indicative of liver damage ${ }^{12,13}$. These enzymes are located in the cell cytoplasm and are emptied into the circulation once the cellular membrane is damaged ${ }^{14,15}$. There is a growing consensus among workers that $\mathrm{CC}_{4}$ - induced liver damage occur by the production of a trichloromethyl radical from $\mathrm{CCl}_{4}$ when it is reductively dechlorinated. The trichloromethyl radical production abstracts a hydrogen atom from fatty acid to form a lipid radical that reacts with molecular oxygen. The product of such reaction is the initiation of lipid peroxidation $^{16,17}$.

Since the above mechanism is suggestive of the process of oxidative stress, it is true, therefore, that any natural product with antioxidant property will prevent or reverse lipid peroxidation; including cell membrane damage. The report of $\mathrm{Iwu}^{4}$ that implicated seeds of Garcinia kola in folk medicine and herbal preparations for treatment of liver disorders, informed the screening of its natural antioxidant properties. We also reasoned that a comparison of the results obtained with those of vitamin E (rated as one of the most powerful antioxidants) would positively influence our position on its antioxidant status.

The findings in this study shows that pretreatment of rats 21 days prior to $\mathrm{CC}_{4}$ administration caused a marked decrease in the levels of hepatospecific serum enzymes. This suggests that seeds of Garcinia kola may be protective against $\mathrm{CCl}_{4^{-}}$induced liver damage in rats. This was ascertained by a comparative analysis of the results obtained in rats pretreated with Garcinia kola and vitamin $\mathrm{E}$.

Malodialdehyde (MDA) is a product of lipid peroxidation ${ }^{9}$. An increase in the liver MDA levels is an indication of elevated level of lipid peroxidation ${ }^{17}$. Extensive lipid peroxidation leads to disorganization of membrane by peroxidation of unsaturated fatty acids which also alters the ratio of poly-unsaturated to other fatty acids. This would lead to a decrease in the membrane fluidity and the death of cell ${ }^{9}$.

\section{Conclusion}

The marked decrease in the levels of lipid peroxides recorded in rats pretreated with Garcinia kola seeds suggests that the seed may possess the natural antioxidants necessary for protection against free radical damage induced by $\mathrm{CC}_{4}$ in rat liver.

\section{REFERENCES}

1.Hukkeri, V. I., Jaiprakash, B., Lavhale, M. S., Karadi, R. V. and Kuppast, I. J. (2003) Hepatoprotective activity of Ailanthus excelsa Roxb. Leaf extract on experimental liver damage in rats. Pharmacognosy 11:12.

2.Terashima, K., Takawa, Y. and Niwa, M. (2002) Powerful antioxidative agents based 
on Garcinonic acid from Garcinia kola. Bio. Org. Med. Chm. 10:1619-1625.

3.Iwu, M.M., Igboko, O. A., Onwuchekwu, U. and Okunji, C. O (1987) Evaluation of the antihepatoxicity of the biflavonoidsGarcinia Kola seeds. J. Ethnopharmacol. 21:127-142.

4.Iwu, M. M. (1982) Traditional Igbo Medicine. Institute of African studies, University of Nigeria, Nsukka, p.104.

5.Reinke L. A., Lai, E.K. and McCay, P. B. (1988) Ethanol feeding stimulates trichloromethyl radical formation from carbon tetrachloride in liver. Xenobiotics 18:1311-1318.

6.Onyeike, E. N. and Omubo-dede, T.T. (2002) Effects of heat treatment on the proximate composition, energy values, and levels of some toxicants in African yam bean (Sphenostylis stencocarpa) seed varieties. Plant foods for human nutrition 57:223-231.

7.Obi, F.O., Usenu, L.A., and Osayande, J.O. (1998) Prevention of carbon tertrachloride induced hepatotocixity in the rat by H.rosainensis anthocyanin extract administered in ethanol. Toxicology 131:9398.

8.Verly, H. (1967) Practical clinical Biochemistry, $4^{\text {th }}$ ed. Heinemann, London, Pp. 891-921.

9.Devaki, T., Raghavendran, H.R.B. and Sathivel, A. (2004) Hepatoprotective nature of seaweed alcoholic extract on acetaminophen-induced hepatic oxidative stress. J. Hlth. Sci. 50:42 - 46.

10.Hunter, F.E., Gebicki, J. M., Hoffstein, P.E., Weinstein J., and Scolt, A. (1963) Swelling and Lysis of rat liver mitochondria induced by ferrous ions. J. Biol. Chem. 238:828-835.

11.Gutteridge, J.M.C. and Wilkins, C. (1982) Copper dependent hydroxyl radical damage to ascorbic acid: Formation of a thiobarbituric acid reactive products. FEBS Lett: 137:327-340.
12.Lin, J. K. and Wang, C. J. (1986) Protection of crocein dyes in the acute hepatic damage induced by aflatoxin B1 and dimethylnitrosamine in rats. Carcinogenesis 7: 595-599.

13.Ngaha, E.O., Akanji, M. A. and Madusuolunmo, M.A. (1989) Studies on correlation between chloroquine-induced tissue damage and serum enzyme changes in rat. Experimentia 45:143-146.

14.Mohan-Rao, G.M., Morghmom, L.O., Kabur, M.N., Benmohamud, B.M. and Ashibanic, K.C. (1989) Serum glutamic, oxaloacetic transaminase (GOT) and glutamic pyruvic transminase (GPT) levels in diabetes mellitus. Int. J. Med. Sci. 5:188192.

15.Lin, S. C., Chung, T. C., Ueng, T.H., Linn, Y.H., Hsu, S.H., Chiang, C.L. and Lin, C.C. (2000) The hepatoprotective effects of Solnum alatam moench on acetaminophen0induced hepatotoxicity in mice. Am. J. Clin. Med. 28:105-114.

16.Sipes, I. G., Krishna, G. and Gillette, J. R. (1977) Bioactivation of carbon tetrachloride, chloroform and bromotrichloromethane: role of cytochrome $\mathrm{P}_{450}$. Life Sci. 20:1541-1548.

17.Trible, D. L., AW, T.Y. and Jones, D.P. (1987) The pathophysiological significance of lipid peroxidation in oxidative cell injury. Hepatology 7:377-387. 